\title{
Resveratrol-procyanidin blend: nutraceutical and antiaging efficacy evaluated in a placebo- controlled, double-blind study
}

This article was published in the following Dove Press journal:

Clinical, Cosmetic and Investigational Dermatology

4 October 2012

Number of times this article has been viewed

\section{Daniela Buonocore \\ Angelo Lazzeretti ${ }^{2}$ \\ Pedro Tocabens ${ }^{3}$ \\ Vincenzo Nobile ${ }^{4}$ \\ Enza Cestone ${ }^{4}$ \\ Giada Santin ${ }^{5}$ \\ Maria G Bottone $e^{5,6}$ \\ Fulvio Marzatico'}

'Laboratory of Pharmacobiochemistry, Nutrition and Nutraceutical of

Wellness, Department of Biology and Biotechnology "L Spallanzani", University of Pavia, Pavia, Italy; ${ }^{2}$ GMC Pharma SRL, Milan, Italy; ${ }^{3}$ Actafarma Laboratorios, Madrid, Spain; ${ }^{4}$ Farcoderm SRL European Network for Tests in Dermatology and Wellness, Pavia, ${ }^{5}$ Laboratory of Cell Biology and Neurobiology, Department of Biology and Biotechnology “L Spallanzani”, ${ }^{6}$ Institute of Molecular Biology CNR, Section of Histochemistry and Cytometry, University of Pavia, Pavia, Italy
Correspondence: Daniela Buonocore Laboratory of Pharmacobiochemistry, Nutrition and Nutraceutical of Wellness, University of Pavia, via Ferrata 9,

Pavia, Italy 27100

Tel +3903 82986468 ext 6390

Fax +390382986390

Email farmbio@unipv.it
Background: Skin is constantly exposed to pro-oxidant environmental stress from several sources, including air pollutants, ultraviolet solar light, and chemical oxidants. Reactive oxygen species have been implicated in age-related skin disorders. Dietary bioactive antioxidant compounds, such as polyphenols, have beneficial effects on skin health. The advantage of a nutritional administration route is that blood delivers nutraceutical bioactive compounds continuously to all skin compartments, ie, the epidermis, dermis, and subcutaneous fat. The purpose of this study was to evaluate the topical and systemic effects of a dietary supplement containing resveratrol and procyanidin on age-related alterations to the skin, the skin antioxidant pool, and systemic oxidative stress levels.

Methods: An instrumental study was performed in 50 subjects ( 25 treated with supplements and 25 with placebo) to identify clinical features induced by chronoaging or photoaging. Product efficacy was evaluated after 60 days of treatment in terms of in vivo and in situ skin hydration, elasticity, and skin roughness levels, systemic oxidative stress levels by plasmatic derivatives of reactive oxygen metabolites and oxyadsorbent tests, and extent of the skin antioxidant pool.

Results: After 60 days of treatment, values for systemic oxidative stress, plasmatic antioxidant capacity, and skin antioxidant power had increased significantly. Additionally, skin moisturization and elasticity had improved, while skin roughness and depth of wrinkles had diminished. Intensity of age spots had significantly decreased, as evidenced by improvement in the individual typological angle.

Conclusion: Nutraceutical and pharmacological intervention with a supplement characterized by a specific blend of resveratrol and procyanidin may be a promising strategy to support treatments for the reduction of skin wrinkling, as well as reducing systemic and skin oxidative stress.

Keywords: antiaging, nutraceuticals, procyanidin, resveratrol supplementation, skin

\section{Introduction}

Antioxidants are a very large category of substances, because many chemical entities may exert a direct or indirect antioxidant activity. A dietary antioxidant is a food substance that significantly reduces the adverse effects of reactive oxygen species and/or reactive nitrogen species on normal human physiological functioning. ${ }^{1}$ Human skin is continuously exposed to internal and external influences that may alter its condition and functioning. As a consequence, the skin may undergo alterations that, in turn, lead to chronoaging, photoaging, inflammation, and immune dysfunction, and all these processes are mediated by reactive oxygen species. Reactive oxygen species are generated constantly in the skin, and are rapidly neutralized both by nonenzymatic 
(vitamins $\mathrm{C}$ and $\mathrm{E}$, A provitamins, eg, beta-carotene) and by antioxidant enzymatic activity $(\mathrm{Zn} / \mathrm{Cu}$ and $\mathrm{Mn}$ superoxide dismutase, glutathione peroxidases, and catalase). The combined functioning of these systems and substances maintains a good antioxidant balance., ${ }^{2,3}$

In recent years, various polyphenols that occur naturally in plant foods, including fruit, vegetables, nuts, seeds, flowers, and bark, have gained considerable attention as a means to neutralize reactive oxygen species. ${ }^{4}$ Resveratrol, ${ }^{5,6}$ green tea, ${ }^{7,8}$ curcumin, ${ }^{9}$ ginger, ${ }^{10,11}$ and diets rich in bioactive compounds such as vitamins $\mathrm{C}$ and $\mathrm{E}$, beta-carotene, lycopene, $\mathrm{Zn}$, and Se, afford protection against the development of skin cancer, inflammation, chronoaging, and photoaging in humans. ${ }^{12-15}$ Over the past decade, resveratrol (3,5,40-trihydroxystilbene), a polyphenol found in grapes (Vitis vinifera) and in a variety of berries, peanuts, and medicinal plants, such as Japanese knotweed (Polygonum cuspidatum), has received widespread attention as a preventive agent against numerous diseases. The few human clinical trials that are available have described resveratrol in terms of safety and bioavailability. Despite the apparent interest in resveratrol as a skin antiaging compound, the literature on this issue is at a nascent stage. A few in vitro studies indicate that resveratrol protects normal human fibroblasts from the damaging effects of hydrogen peroxide in a dose-dependent manner, ${ }^{16}$ possibly by binding of specific receptors in the epidermis. ${ }^{17}$

Clinical data on the usefulness of topical formulations containing resveratrol ${ }^{18}$ are available but limited. Polyphenols, such as procyanidin, anthocyanidin, and ellagic acid, are associated with a beneficial effect on the skin. ${ }^{19,20}$ However, it is still to be established what the exact mechanism of action is, ie, whether this action takes place directly via an increase in skin polyphenol content or indirectly through a systemic effect on the vascular system. The goal of the current study was to determine whether chronic nutraceutical treatment with a supplement composed of resveratrol, procyanidin, ellagic acid, selenium, and other phenols in smaller quantities is able to improve systemic and skin antioxidant capacity and promote skin antiaging effects by improving hydration, elasticity, and skin roughness.

\section{Materials and methods}

All procedures were approved by an independent ethical committee for nonpharmacological research. Each subject recruited for the study was fully informed and treated in accordance with the guidelines of the Declaration of Helsinki (as revised in Tokyo, 2004).

\section{Subjects and study design}

The study enrolled 50 healthy males and females aged 35-65 years, all of whom showed clinical signs of skin aging (wrinkles, dull complexion, brown spots). Table 1 reports the study inclusion criteria. Each qualifying subject was then randomized to a study group (active or placebo). The test product or matching placebo were taken as one capsule per day for 60 days. Food intake was monitored day by day using a food diary. All the samples used for skin tests were applied to the facial skin. The product tested was a commercial dietary supplement named Revidox ${ }^{\circledR}$ (GMC Pharma, Milan, Actafarma Laboratorios, Madrid).

One capsule of supplement contains $133 \mathrm{mg}$ grape ( $V$. vinifera) dried fruit extract from a patented production process (which in turn contains $8 \mathrm{mg}$ transresveratrol), $14.63 \mathrm{mg}$ procyanidins, $0.67 \mathrm{mg}$ anthocyanosides, $0.4 \mathrm{mg}$ flavonoids, $1.3 \mathrm{mg}$ other stilbenes, $125 \mathrm{mg}$ pomegranate (Punica granatum) dried fruit extract (which in turn contains $3.75 \mathrm{mg}$ procyanidins), $8.75 \mathrm{mg}$ punicalagin-ellagic acid, $50 \mu \mathrm{g}$ selenium, $26 \mathrm{mg}$ silicon dioxide, and $45 \mathrm{mg}$ maltodextrin. Placebo was formulated as follows: $266 \mathrm{mg}$ dehydrated dibasic calcium phosphate, $18 \mathrm{mg}$ pigment red iron oxide (E 172), $4 \mathrm{mg}$ magnesium stearate, $4 \mathrm{mg}$ amorphous precipitated silica, and $77 \mathrm{mg}$ activated charcoal.

\section{Antioxidant evaluation}

Plasmatic (derivatives of reactive oxygen metabolites [d-ROMs] and oxyadsorbent assay) and skin antioxidant (ferric-reducing ability of plasma assay) tests were performed. After enrollment, venous blood and skin samples were collected. Blood samples were collected after an overnight

Table I Inclusion criteria

Healthy female (70\%) and male (30\%) subjects

Age $35-65$ years ( $50 \%$ aged $35-50$ years and $50 \%$ aged $5 \mathrm{I}-65$ years)

Caucasian race

Dull complexion

Body mass index in the optimal (20-25) range for both male and female subjects

Cutaneous dyschromia/brown spots (present in at least $60 \%$ of participants) Subjects who have not participated in similar studies in the 2 months prior to the current study Absence of skin diseases

Undertaking not to change their normal daily routine

Commitment not to use products having activity comparable with that

of the product to be tested during the study period

Commitment not to use face creams during the study period

Promise not to change eating habits during the study period

Agreeable to signing an informed consent form 
fast and abstinence from cigarette smoking. Plasma was then isolated at room temperature and, after centrifugation $\left(2000 \times \mathrm{g}, 20\right.$ minutes at $\left.25^{\circ} \mathrm{C}\right)$, was kept frozen at $-80^{\circ} \mathrm{C}$ until analysis. Skin samples were collected using Corneofix ${ }^{\circledR}$ (Courage and Khazaka Electronic GmbH, Cologne, Germany) foils. After collection, skin samples were kept frozen at $-80^{\circ} \mathrm{C}$ until analysis. d-ROMs levels in plasma were assessed using a commercially available method (Diacron, Grosseto, Italy $)^{21}$ in accordance with the supplier's instructions. Normal test values range between 250 and 300 UCARR (Carratelli units), where 1 UCARR corresponds to $0.8 \mathrm{mg} / \mathrm{L} \mathrm{H}_{2} \mathrm{O}_{2}$. Values $>300$ UCARR indicate oxidative stress. The plasmatic "barrier to oxidation" was assessed using a commercially available oxyadsorbent test (Diacron) ${ }^{22}$ in accordance with the supplier's instructions. Normal test values are $>350 \mathrm{mmol} / \mathrm{L}$. Values $<350 \mathrm{mmol} / \mathrm{L}$ indicate oxidative stress deriving from a decrease in antioxidant defenses. The antioxidant power of the skin was assessed on the third and fourth skin strips (Corneofix after discarding the first and second layers). Briefly, $0.4 \mathrm{~mL}$ of ferric-reducing ability of plasma working solution $(300 \mathrm{mmol} / \mathrm{L} \mathrm{pH} 3.6$ acetate buffer, $10 \mathrm{mmol} / \mathrm{L}$ 2,4,6-tripyridyl-s-triazine in $40 \mathrm{mmol} / \mathrm{L} \mathrm{HCl}$, and $20 \mathrm{mmol} / \mathrm{L}$ $\mathrm{FeCl}_{3} \times 6 \mathrm{H}_{2} \mathrm{O}$ in distilled water $)^{23}$ was added to 12 -multiwell plates, each of which contained two strips of Corneofix (sandwich system). After 30 minutes of incubation at $37^{\circ} \mathrm{C}$, the supernatant was collected and transferred to a $1 \mathrm{~cm}$ light path cuvette, and absorbance was read at $550 \mathrm{~nm}$. An aqueous solution of known $\mathrm{Fe}(\mathrm{II})$ concentration was used for calibration (in the range of 50-1000 $\mu \mathrm{mol} / \mathrm{L}$ ). Dermatological testing was performed after an acclimatization period of at least 15 minutes in a room with controlled temperature $\left(22^{\circ} \mathrm{C} \pm 2{ }^{\circ} \mathrm{C}\right)$ and humidity $(50 \% \pm 10 \%)$.

\section{Skin moisturization}

The corneometer CM 825 (Courage and Khazaka Electronic $\mathrm{GmbH}$ ) was used to measure skin moisturization. ${ }^{24}$ Measurements were taken at five different sites on the cheek. The arithmetic mean for each volunteer and time point was calculated. Measurements of skin hydration were performed in accordance with the recommendations of the European Group for Efficacy Measurements on Cosmetics and Other Topical Products. ${ }^{25}$

\section{Skin elasticity}

The Cutometer MPA580, equipped with a $2 \mathrm{~mm}$ measuring probe (Courage and Khazaka Electronic $\mathrm{GmbH}$ ) was used to measure skin elasticity. ${ }^{26}$

\section{Skin surface}

The skin surface was quantitatively assessed using a Primos 3D (GF Messtechnik GmbH, Berlin, Germany) equipped with a stereotactic device (Canfield Imaging System, Fairfield, NJ). The Primos 3D is a noncontact in vivo skin measurement device based on structured light projection. ${ }^{27}$ In conjunction with comprehensive three-dimensional measurement and evaluation software, the sensor enables evaluation of skin surface properties (ie, wrinkle depth, roughness). Skin roughness (Rz, ISO 4287, DIN 4768) and wrinkle depth were analyzed using the Primos 3D software. Skin damage results in a higher roughness value. ${ }^{28,29}$

\section{Brown spot intensity}

The brown spot intensity was assessed using a spectrophotometer/colorimeter (CM-700D, Konica-Minolta, Tokyo, Japan). $\mathrm{L}^{*}$ and $\mathrm{b}^{*}$ values were measured and interpolated with a mathematical formula that allows calculation of the individual typological angle. ${ }^{30}$

\section{Data analysis}

Statistical analysis for differences between treatment times was conducted using the two-way Student's $t$-test, and oneway analysis of variance was used for differences between groups. A difference was considered to be statistically significant at $P<0.05$. A study power analysis was performed.

\section{Results}

Fifty healthy females and males (comprising 70\% and 30\% of the cohort, respectively) completed the study. In both the treatment and placebo groups, each subject was evaluated at baseline and at the end of the 60-day treatment period. Throughout the study, the subjects undertook periodic selfassessment on a normal diet. After 60 days of treatment, systemic oxidative stress had decreased significantly, and the d-ROMs value had changed from medium oxidative stress (Carratelli scale) to normal oxidative stress $(P=0.001)$. Furthermore, the plasmatic derivative metabolites of hydroperoxide value had reduced significantly $(P=0.001)$ in comparison with that in the placebo group (Figure 1A). Antioxidant capacity (oxyadsorbent test, plasmatic barrier to oxidation) at the end of the study period had improved to normal $(P=0.001)$, and improvement in the treated group was significantly higher than that in the placebo group $(P=0.001$, Figure 1B). The antioxidant power of the skin improved in the treated group after 60 days of treatment 

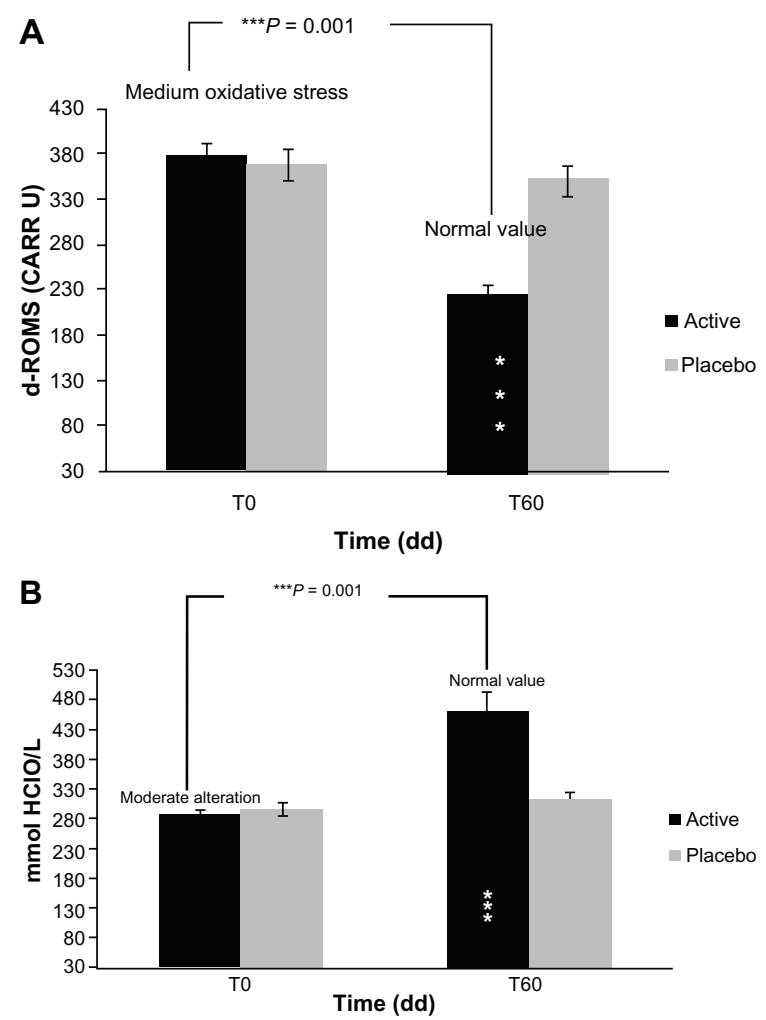

Figure I Antioxidant evaluation. (A) Derivatives of reactive oxygen metabolites test (Carratelli units). (B) Oxyadsorbent test ( $\mathrm{mmol} \mathrm{HClO} / \mathrm{L})$ both as a function of time in days $(\mathrm{dd})$

Notes: Data are reported as the mean \pm standard error of the mean. Intergroup statistical analysis (active versus placebo) is reported inside the bars of the histogram. The lines report the intragroup statistical analysis (T60 vs T0). Statistical analysis is marked with $(*)$ in increasing numbers depending on significance.

Abbreviation: $d-R O M s$, derivatives of reactive oxygen metabolites test.

$(P=0.001)$, and levels of skin antioxidants were significantly higher than in the placebo group $(P=0.001$, Figure 2$)$. In the treated group, skin moisturization improved, with dry skin achieving a moisturized condition $(P=0.001)$, while placebo subjects did not show improved moisturization, and remained

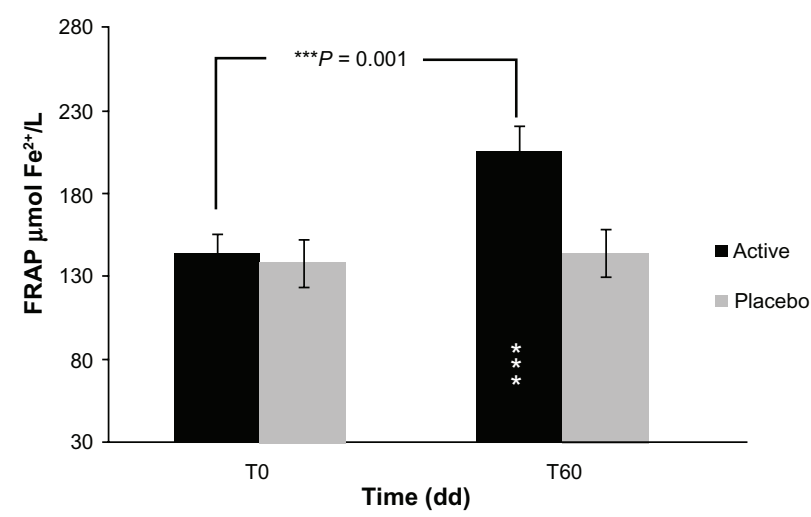

Figure 2 Skin Antioxidant capacity: FRAP test- $\left(\mu \mathrm{mol} \mathrm{Fe}^{2+} / \mathrm{L}\right)$ as a function of time in days $(\mathrm{dd})$.

Notes: Data are reported as mean \pm SEM. Intergroup statistical analysis (active vs placebo) is reported inside the bars of the histogram. The lines report the intragroup statistical analysis (T60 vs T0). Statistical analysis is marked with $\left(^{*}\right)$ in increasing numbers depending on significance.

Abbreviation: FRAP test, ferric-reducing ability of plasma test. significantly less moisturized $(P=0.001$, Figure $3 \mathrm{~A})$ than the treated group. Skin elasticity improved in the treated group $(P=0.001)$ but deteriorated slightly but significantly in the placebo group $(P=0.05$, Figure 3B). Skin roughness diminished significantly $(P=0.01)$ in the treated group, as did wrinkle depth $(P=0.01)$, but these parameters were significantly worse $(P=0.01)$ in the placebo group (Figure 4A and B). Finally, the intensity of age spots in the treated group diminished significantly (individual typological angle grade, $P=0.01$ ) and to a significantly greater extent than in the placebo group $(P=0.01$, Figure 5).

\section{Discussion}

Bioactive food compounds (nutrients and phytochemicals) at pharmacological doses are emerging as a therapy to modulate the complex sequence of metabolic changes associated with skin and systemic aging. This "nutraceutical" treatment can efficiently modulate the oxidative and inflammatory imbalances that occur in chronic aging. ${ }^{31,32}$ However,
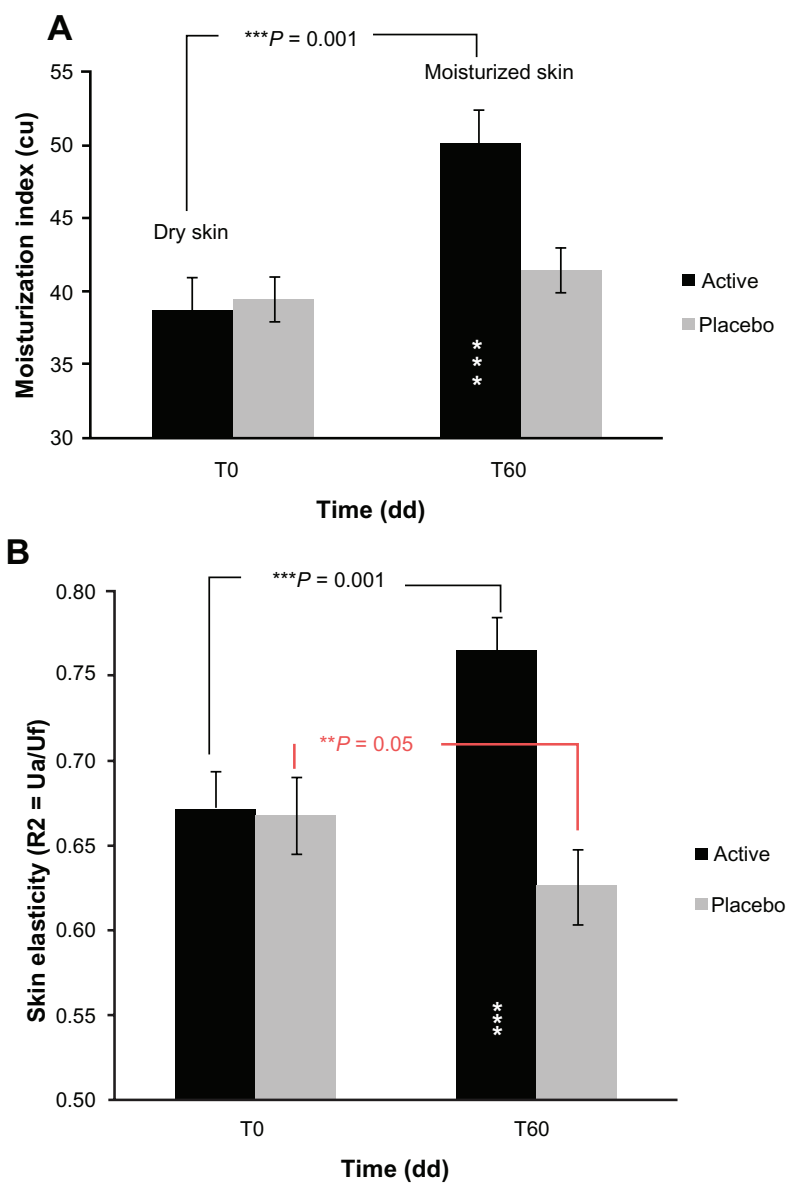

Figure 3 Skin antiaging effect. (A) Skin moisturization (corneometric units). (B) Skin elasticity (R2 parameter) - ( $\mathrm{Ua} / \mathrm{Uf}$ ratio) both as a function of time in days (dd).

Notes: Data are reported as the mean \pm standard error of the mean. Intergroup statistical analysis (active versus placebo) is reported inside the bars of the histogram. The lines report the intragroup statistical analysis (T60 vs T0). Statistical analysis is marked with $\left(^{*}\right)$ in increasing numbers depending on significance. 


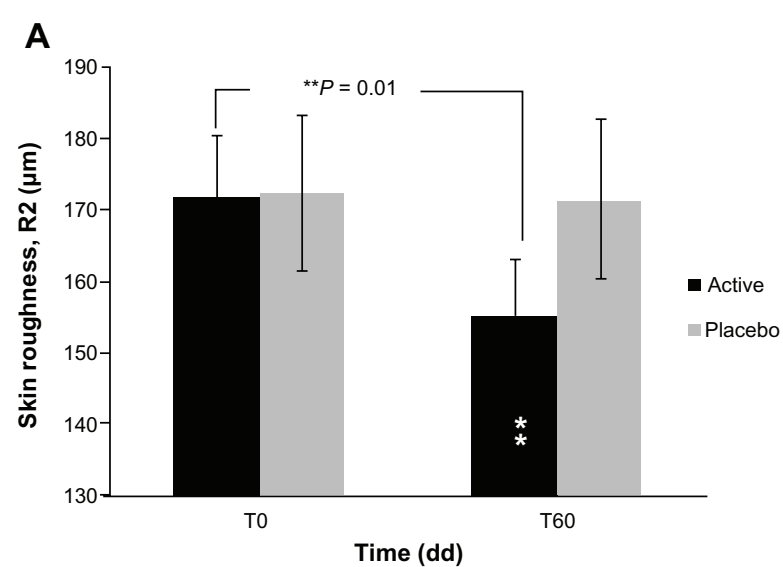

B

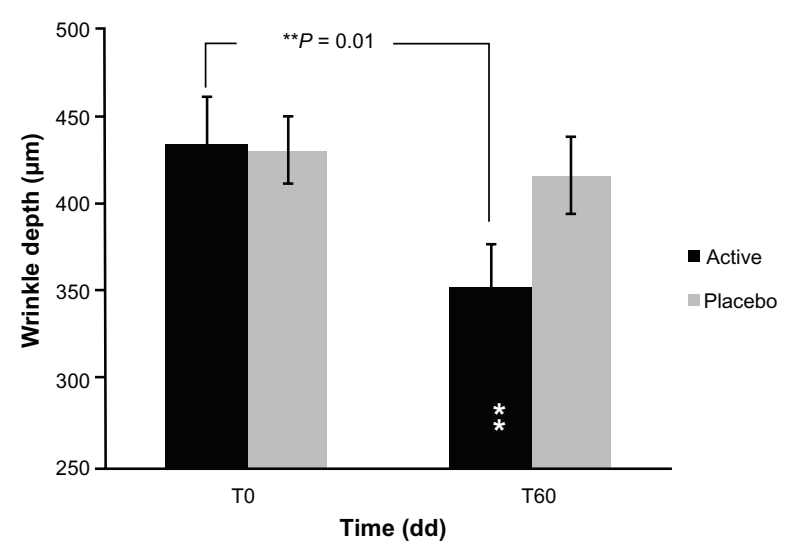

Figure 4 Skin surface $(\mu \mathrm{m})$. (A) Skin roughness. (B) Wrinkle depth, both as a function of time in days (dd).

Notes: Data are reported as the mean \pm standard error of the mean. Intergroup statistical analysis (active versus placebo) is reported inside the bars of the histogram. The lines report the intragroup statistical analysis (T60 vs T0). Statistical analysis is marked with $\left(^{*}\right)$ in increasing numbers depending on significance.

food sources are complex, with varying combinations of compounds inducing similarly varying capacity to enhance or reduce bioavailability and/or activity. ${ }^{31,33}$ Therefore, the benefits of dietary constituents may differ if the same bioactive substances are present in nutraceutical formulations at pharmacological doses. In the case of the skin, the classical route of antioxidant administration is topical application.

Another means by which to deliver antioxidants to the skin is oral administration via the diet and dietary supplements. ${ }^{34}$ An increase in cellular antioxidants in the skin is observed after oral administration of antioxidant supplements, whereby antioxidants cross the intestinal barrier and reach the circulation, after which they are distributed to various tissues, in particular to the subcutaneous adipose tissue, dermis, epidermis and sebum in the skin.

The multiple mechanisms of action of resveratrol may be related to its health benefits. ${ }^{35}$ Like most polyphenols, this phytochemical has intrinsic antioxidant capacity, but it also induces expression of a number of antioxidant enzymes. Further, it interacts with a large number of receptors and kinases,

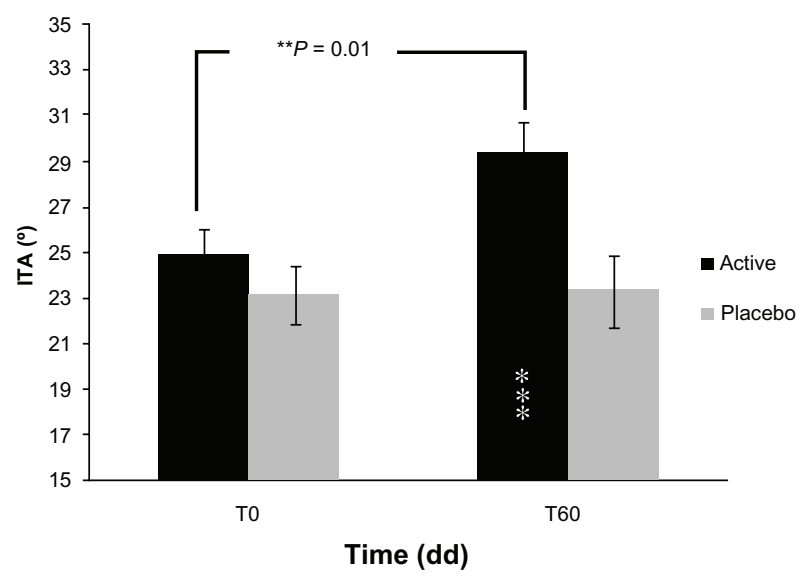

Figure 5 Intensity of brown spot: $\operatorname{ITA}^{\circ}$ - grades $\left({ }^{\circ}\right)$ as a function of time in days (dd). Notes: Data are reported as the mean \pm standard error of the mean. Intergroup statistical analysis (active versus placebo) is reported inside the bars of the histogram. The lines report the intragroup statistical analysis (T60 vs T0). Statistical analysis is marked with $(*)$ in increasing numbers depending on significance.

including sirtuin 1 and adenosine monophosphate-activated protein kinase, both of which influence the regulation of metabolism in multiple tissues. ${ }^{36,37}$ Accordingly, it is difficult to decipher the precise contribution of each mechanism to an overall multiple effect on health. ${ }^{38}$

Two recent and important clinical studies of resveratrol have shown that different effects are obtained with different doses of resveratrol; specifically, at lower doses, it is very important to mix this compound with other flavonoids. However, to date, no clinical study has shed light on the effects of resveratrol in the field of dermatological antiaging. ${ }^{39,40}$ Our study provides the first clinical proof of the antiaging effects of a chronic nutraceutical treatment that combines resveratrol and procyanidins. Hitherto, attempts to reveal and understand the skin-repairing effects of resveratrol were cosmeceutically oriented. ${ }^{41}$ Although the bioavailability of resveratrol in particular and of polyphenols in general is low, treatment with this nutraceutical supplement for 60 days improved parameters of oxidative stress by reducing systemic peroxidized metabolites and by improving the plasma antioxidant barrier.

The current range of nutraceutical dosages of resveratrol (20-500 mg per capsule) is probably disproportionate. Dietary intake is $6-8 \mathrm{mg}$ daily, and recent clinical data show that resveratrol may possess bioactivity at $\mu \mathrm{g}$ doses, when provided as part of a synergistic combination of phytochemicals in foods and supplements. Accordingly, the use of supplements that bring the dose into a medium to low range may have specific effects on the aging process. ${ }^{42}$ In addition, our study is the first to demonstrate that, as well as improving systemic oxidative stress, antioxidant nutraceutical treatment also enhances antioxidant capacity in the stratum corneum of the skin. We used the withdrawal 
technique for the skin stratum corneum, as has already been described for the assessment of antioxidant enzymes and adapted to the evaluation of reducing antioxidant capacity in skin samples. ${ }^{43,44}$ Wrinkle formation occurs because of accumulated forms of skin damage, including matrix destruction and skin inflammation. In aging skin, there are various activated matrix metalloproteinases that lead to abnormal matrix degradation and to accumulation of nonfunctional matrix components in the dermal and epidermal compartments. ${ }^{45}$ Recently, foods rich in flavonoids and ellagic acid have been shown to reduce the action of metalloproteinases and to improve the appearance of wrinkles. ${ }^{46}$ Finally, our study shows that chronic treatment with a nutraceutical supplement containing resveratrol, procyanidin, and ellagic acid for 60 days significantly improved all parameters related to skin roughness.

\section{Acknowledgment}

Thanks are due to GMC Pharma, Milan, and Actafarma Laboratorios, Madrid, for providing the sample formulation tested in this study. The authors are also grateful to all the volunteers who made this work possible.

\section{Disclosure}

The authors report no conflicts of interest in this work.

\section{References}

1. Food and Nutrition Board, Institute of Medicine. Dietary Reference Intakes. Washington, DC: National Academy Press; 2002.

2. Steenvoorden DP, van Henegouwen GM. The use of endogenous antioxidants to improve photoprotection. J Photochem Photobiol. 1997; $41: 1-10$.

3. Thiele JJ, Dreher F, Packer L. Cosmeceuticals. In: Elsner P, Maibach H. Drugs vs Cosmetics. New York, NY: Dekker; 2000.

4. Sies H. Polyphenols and health: update and perspectives. Arch Biochem Biophys. 2010;501:2-5.

5. Kiselev KV. Perspectives for production and application of resveratrol. Appl Microbiol Biotechnol. 2011;90:417-425.

6. Agarwal B, Bauer JA. Resveratrol and life extension. Ann N Y Acad Sci. 2011;1215:138-143.

7. Chen D, Wan SB, Yang H, et al. EGCG green tea polyphenol and their synthetic analogs for human cancer prevention and treatment. Adv Clin Chem. 2011;53:155-177.

8. Wang Y, Ho CT. Polyphenolic chemistry of tea and coffee: a century of progress. J Agric Food Chem. 2009;57:8109-8114.

9. Zhou H, Beevers CS, Huang S. The targets of curcumin. Curr Drug Targets. 2011;12:332-347.

10. Katiyar SK, Agarwal R, Mukhtar H. Inhibition of tumor promotion in SENCAR mouse skin by ethanol extract of Zingiber officinale rhizome. Cancer Res. 1996;56:1023-1030.

11. Surh Y. Molecular mechanisms of chemopreventive effects of selected dietary and medicinal phenolic substances. Mutat Res. 1999;428: 305-327.

12. McKenzie RC. Selenium, ultraviolet radiation and the skin. Clin Exp Dermatol. 2000;25:631-636.

13. Stahl W, Sies H. Carotenoids and protection against solar UV radiation. Skin Pharmacol Appl Skin Physiol. 2002;15:291-296.
14. Cesarini JP, Michel L, Maurette JM, et al. Immediate effects of UV radiation on the skin: modification by an antioxidant complex containing carotenoids. Photodermatol Photoimmunol Photomed. 2003;19: 182-189.

15. Guo W, Kong E, Meydani M. Dietary polyphenol, inflammation and cancer. Nutr Cancer. 2009;61:807-810.

16. Jagdeo J, Adams L, Lev Tov H, et al. Dose-dependent antioxidant function of resveratrol demonstrated via modulation of reactive oxygen species in normal human skin fibroblast in vitro. J Drugs Dermatol. 2010;9:1523-1526.

17. Bastianetto S, Dumont Y, Duranton A, et al. Protective action of resveratrol in human skin: possible involvement of specific receptor binding sites. PLoS One. 2010;5:e12935.

18. Baxter RA. Anti-aging properties of resveratrol: review and report of a potent new antioxidant skin care formulation. J Cosmet Dermatol. 2008:7:2-7.

19. Wie H, Saladi R, Lu Y, et al. Isoflavone genistein: photoprotection and clinical implications in dermatology. J Nutr. 2003;133(11 Suppl 1): S3811-S3819.

20. Kenny TP, Keen CL, Jones P, et al. Cocoa procyanidins inhibit proliferation and angiogenic signals in human dermal microvascular endothelial cells following stimulation by low-level $\mathrm{H}_{2} \mathrm{O}_{2}$. Exp Biol Med. 2004;229:765-771

21. Cesarone MR, Belcaro G, Carratelli M, et al. A simple test to monitor oxidative stress. Int Angiol. 1999;18:127-130.

22. Vassalle C, Masini S, Carpeggiani C, et al. In vivo total antioxidant capacity: comparison of two different analytical methods. Clin Chem Lab Med. 2004;42:84-89.

23. Benzie IFF, Strain JJ. The ferric reducing ability of plasma (FRAP) as a measure of "antioxidant power": the FRAP assay. Anal Biochem. 1996;239:70-76.

24. Courage W. Hardware and measuring principle: corneometer. In: Elsner P, Berardesca E, Maibach HI, editors. Bioengineering of the Skin: Water and the Stratum Corneum. London, UK: CRC Press; 1994.

25. Berardesca E. EEMCO guidance for the assessment of stratum corneum hydration: electrical methods. Skin Research and Technology. 1997;3: 126-132.

26. Barel AO, Courage W, Clarys P. Suction method for measurement of skin mechanical properties: the cutometer. In: Serup J, Jemec GBE, editors. Handbook of Non-Invasive Methods and the Skin. Boca Raton, FL: CRC Press; 1995.

27. Fujimura T, Haketa K, Hotta M, et al. Global and systematic demonstration for the practical usage of a direct in vivo measurement system to evaluate wrinkles. Int J Cosmet Sci. 2007;29:423-436.

28. Hoppe U, Lunderstädt R, Sauermann G. Quantitative analysis of the skin's surface by digital processing. In: Frosch PJ, Kligman AM, editors. Noninvasive Methods for the Quantification of Skin Functions. Heidelberg, Germany: Springer; 1993.

29. Wilhelm KP, Elsner P, Berardesca E, Maibach HI. Bioengineering of the Skin: Skin Surface Imaging and Analysis. Boca Raton, FL: CRC Press; 1996.

30. COLIPA Guidelines. Guideline for Colometric Determination of Skin Colour Typing and Prediction of the Minimal Erythemal Dose (MED) Without UV Exposure. European Cosmetic, Toiletry and Perfumery Association; 2007.

31. Aggarwal BB. Targeting inflammation-induced obesity and metabolic diseases by curcumin and other nutraceuticals. Annu Rev Nutr. 2010; 30:173-199.

32. Prasad S, Phromnoi K, Yadav VR, et al. Targeting inflammatory pathways by flavonoids for prevention and treatment of cancer. Planta Med. 2010;76:1044-1063.

33. Anand P, Kunnumakara A, Sundaram C, et al. Cancer is a preventable disease that requires major lifestyle changes. Pharm Res. 2008;25: 2097-2116.

34. Richelle M, Sabatier M, Steiling H, et al. Skin bioavailability of dietary vitamin $\mathrm{E}$, carotenoids, polyphenols, vitamin $\mathrm{C}$, zinc and selenium. Br J Nutr. 2006;96:227-238. 
35. Baur JA, Sinclair DA. Therapeutic potential of resveratrol: the in vivo evidence. Nat Rev Drug Discov. 2006;5:493-506.

36. Lagouge M, Argmann C, Gerhart-Hines Z, et al. Resveratrol improves mitochondrial function and protects against metabolic disease by activating SIRT1 and PGC-1alpha. Cell. 2006;127:1109-1122.

37. Zang M, Xu S, Maitland-Toolan KA, et al. Polyphenols stimulate AMP-activated protein kinase, lower lipids, and inhibit accelerated atherosclerosis in diabetic LDL receptor-deficient mice. Diabetes. 2006; 55:2180-2191.

38. Halliwell B. Dietary polyphenols: good, bad, or indifferent for your health? Cardiovasc Res. 2007;73:341-347.

39. Smoliga JM, Baur JA, Hausenblas HA. Resveratrol and health: a comprehensive review of human clinical trials. Mol Nutr Food Res. 2011;55:1-13.

40. Chachay VS, Kirkpatrick CMJ, Hickman IJ, et al. Resveratrol - pills to replace a healthy diet? Br J Clin Pharmacol. 2011;72:27-38.

41. Fabbrocini G, Staibano S, De Rosa G, et al. Resveratrol-containing gel for the treatment of acne vulgaris: a single-blind vehicle-controlled, pilot study. Am J Clin Dermatol. 2011;12:133-141.
42. Morris B. Calorie restriction mimetics and aging. In: Everitt AV, Rattan SIS, Couteur DG, de Cabo R, editors. Calorie Restriction, Aging Longevity. Dordrecht, The Netherlands: Springer Publishing; 2010.

43. Giacomoni PU, Declercq L, Hellemans L, et al. Aging of human skin: review of a mechanistic model and first experimental data. IUBMB Life. 2000;49:259-263.

44. Hellemans L, Corstjens H, Neven A, et al. Antioxidant enzyme activity in human stratum corneum shows seasonal variation with an agedependent recovery. J Invest Dermatol. 2003;120:434-439.

45. Pillai S, Oresajo C, Hayward J. Ultraviolet radiation and skin aging: roles of reactive oxygen species, inflammation and protease activation, and strategies for prevention of inflammation-induced matrix degradation. Int J Cosmet Sci. 2005;27:17-34.

46. Bae JY, Choi J-S, Kang S-W, et al. Dietary compound ellagic acid alleviates skin wrinkle and inflammation induced by UV-B irradiation. Exp Dermatol. 2010;19:e182-e190.
Clinical, Cosmetic and Investigational Dermatology

\section{Publish your work in this journal}

Clinical, Cosmetic and Investigational Dermatology is an international, peer-reviewed, open access, online journal that focuses on the latest clinical and experimental research in all aspects of skin disease and cosmetic interventions. All areas of dermatology will be covered; contributions will be welcomed from all clinicians and

\section{Dovepress}

basic science researchers globally. This journal is indexed on CAS The manuscript management system is completely online and includes a very quick and fair peer-review system, which is all easy to use. Visit http://www.dovepress.com/testimonials.php to read real quotes from published authors.

Submit your manuscript here: http://www.dovepress.com/clinical-cosmetic-and-investigational-dermatology-journal 